\title{
"Sitting in the back seat": The convergence of early recollections, self and others, and low socioeconomic class
}

\author{
Mia Levitt-Frank $^{1}$ (D) $\cdot$ Avihu Shoshana $^{1}$
}

Accepted: 24 January 2022

( ) The Author(s), under exclusive licence to Springer Science+Business Media, LLC, part of Springer Nature 2022

\begin{abstract}
This qualitative study examines the links between early recollections, self and others, and low socioeconomic class. Early recollections—-specific memories from childhood—illustrate individuals' core concepts about self and life. Social class is a cultural context that affects psychological processes. We conducted semistructured interviews with 12 low socioeconomic status participants and elicited at least 3 early recollections per participant (totaling 42 recollections). Themes that emerged from analysis of the early recollections include divided reality; creating meaning in the present (including enjoying life and making do with what one has); a parental role of admiration, security, and compensation; and social interest. We regard these strategies as creative assets and mechanisms to deal with a lack of control and resources, sense of constraint, and hierarchical and classed society. We encourage educational and therapeutic frameworks to recognize these assets as facets of psychological and cultural capital.
\end{abstract}

Keywords Social class $\cdot$ Early recollections $\cdot$ Self $\cdot$ Parental role

\section{Introduction}

Individuals' early childhood memories are a cocreation of culture and the self (Wang, 2016) and reflect and shape current perceptions of self and life. Growing up in South Africa in the 1970s, I (first author) remember boarding a doubledecker bus one day. An old man wearing a frayed checkered jacket and his hat on his head slowly climbed the stairs to the second floor. He was black skinned. I was White, 11 years old, and privileged. The law stated that Black people must ride on the top floor. I remember thinking this was not right. How could skin color or social class determine where we sit on the bus? What did he feel? Even more clearly, I remember the knot in my stomach.

This memory is a platform for our research on early recollections (ERs) and social class. Social class is a form of culture that imbues life in the present and affects future outcomes, perpetuating inequality (Bourdieu, 1987; Markus \& Stephens, 2017; Stephens et al., 2014). The psychology of social class regards it as a cultural context that influences

Mia Levitt-Frank

mialefr@gmail.com

1 Department of Counseling and Human Development, University of Haifa, Haifa, Israel the development and structure of the self-an individual's psychological representation of schemas including cognition, emotion, and action. Social class affects individuals' schemas about themselves, others, and the world (Côté, 2011; Manstead, 2018). Sociological studies on class include Lamont and Lareau's (1988) work on cultural capital ("high status cultural signals used in cultural and social selection," p. 153) and social stratification, and Lareau's (2011) and Calarco's (2018) works on class-specific parenting styles, self-concept, and children's skills and strategies.

Studies in North America showed that class differences engender class-specific schemas, for example, an other-oriented and present-focused (low-class) model versus a selforiented and future-focused (high-class) model of the self (Markus \& Stephens, 2017). ERs are subjective metaphoric narratives that reflect current perceptions about the self, others, and life (Sarig, 2016). Research on ERs has focused inter alia on relationships in adulthood between ERs and mental health characteristics, vocational choice, and culture (Sarig, 2016; Wang, 2016). The research on ERs and culture has concentrated on individualism and collectivism in Western and Asian cultures (Wang, 2016). Our study on ERs and high socioeconomic status (SES) revealed classspecific schemas (Levitt-Frank \& Shoshana, 2021). However, our extensive review in the fields of ERs and social 
class revealed no other research on the impact of social class on adult ERs.

Most research in the field of ERs has been quantitative (Frank \& Shoshana, 2019). According to Grossman and Huynh (2013), the majority (85\%) of research on the psychology of class has been conducted in North America. Those authors called for additional research in the field, including in sociocultural contexts other than North American. More recently, Easterbook et al. (2020) invited researchers to focus on the importance of social class to "self and identity processes" (p. 16). Additionally, Mao and Feldman (2019) claimed there was insufficient qualitative research on the psychology of class. Following these leads, this study used a qualitative examination of the links among low SES, the self, and adults' ERs in Israeli society. The purpose of this study was to explore what individuals from low-SES environments remember about their childhoods and how thoughts, behavioral patterns, and emotions are expressed in ERs.

\section{Literature Review}

\section{Social Class, Low SES, and the Self}

Bourdieu (1987) described how economic, social, symbolic, and cultural capital stratify social lives, affect life chances and behavioral strategies, and, with personal dispositions (habitus), create social class. Social class is defined by objective material resources (education, income, occupation) and subjective perceptions of social rank (Côté, 2011). The psychology of social class studies the impact of SES on the self-concept and psychological processes (Manstead, 2018). Individuals from homologous social-class environments tend to embody similar habitus-lifestyles and schemas that appear in early childhood and usually continue through life (Mao \& Feldman, 2019). A sturdy body of studies showed that social class has meaningful psychological attributes that affect the individual's life chances (Lareau, 2011; Manstead, 2018).

Social class generates class-specific ideas of the self and interaction models, characterized in Western cultures by a contextualized, other-oriented model of the self (lower class) or a solipsistic, self-oriented model of the self (higher class; Manstead, 2018). Working-class individuals tend to hold other-oriented psychological tendencies (such as taking others into account), see themselves as interdependent and connected to others, and be present focused. They are more attentive to others' experiences and feelings, display prosocial behavior, and tend to make choices that support similarity as opposed to the uniqueness that characterizes high-SES individuals. The evidence showed that workingclass individuals have a reduced sense of personal control related to situational attributions and tend to show more sensitivity to threats (Carey \& Markus, 2017; Manstead, 2018; Markus \& Stephens, 2017).

Children grow up within a stratified social structure (Lareau, 2011) and, according to Hoff et al. (2002), "parenting differs across socioeconomic strata" (p. 231). Working-class parents facilitate the accomplishment of "natural growth," allowing kids to go out and play and control their leisure time. These parents identify their responsibilities as taking care of basic needs and telling kids what to do in a directive manner, rather than engaging in conversation about feelings, thoughts, and opinions. Working-class children gain a sense of constraint and distrust in interactions in institutional settings and the world (Lareau, 2011).

Snibbe and Markus (2005) suggested that the agency model most common in lower class contexts emphasizes exerting self-control rather than external control and maintaining personal integrity. They claimed that working-class individuals report a subjective sense of satisfaction with life, as do higher class individuals. Tan et al. (2020), however, found in their meta-analytic review of SES that money and resources, reported objectively or perceived subjectively, are related to subjective well-being.

\section{ERs as Metaphoric Narratives About the Self, Life, Others, and Culture}

"Individual memories represent a story of my life" (Adler, 1931, p. 73). An ER is a story of an event the individual remembers, preferably through the age of 10 years. Before age 10, most people do not have continuous memory; therefore, the memory is further revised by projection (Mosak $\&$ Di Pietro, 2006). These ERs are fictional creations constructed by individuals' subjective views about the self, others, and the world and reflect the individual's beliefs, values, behavior strategies, needs, and resources (Mosak \& Di Pietro, 2006; Shifron, 2020).

Literature on the significance of ERs reflects the interest the topic spurs for both practitioners and researchers from various psychological theoretical approaches due to the common understanding that ERs hold important clues to an individual's view of life (Attarian, 1978). Two principal approaches relate ERs as concealing or revealing. Freud referred to screen memories - trivial memories concealing latent traumatic content. Adler focused on the overt content in ERs, seeing them as revealing personality (Clark, 2002; Sarig, 2016). According to Adlerian theory, "People remember only those things that have bearing on their situation" (Mosak \& Di Pietro, 2006, p. 158). This study focused on the Adlerian concept of ERs.

Adler saw ERs as stories about the past told in the present. They enhance individuals' core beliefs and subjective views of the self and life and help them face life's challenges. Adler considered ERs to be goal-oriented metaphoric 
narratives that describe individuals' current life situations or experiences and reveal their personalities, strengths, and primary coping strategies (Sarig, 2016; Shifron, 2020). Comprehensive research has led to using ERs as a projective technique (Mosak \& Di Pietro, 2006).

Since Adler's original observations, researchers have attempted to compile scoring systems that comprehensively assess ERs from different theoretical frameworks (Clark, 2002; Mosak \& Di Pietro, 2006; Sarig, 2016). Initially developed for vocational guidance purposes, the ManasterPerryman (1974) Manifest Content ER Scoring Manual is one of the most widely used systems in ER research. Quantitative studies examined connections between ERs and variables such as personality characteristics (Barrett, 1980), depression (Allers et al., 1992), family constellation, vocational preference (Fakouri \& Hafner, 1984), and cultural coconstruction of the self (Wang, 2016). According to Wang's (2016) studies on cultural differences in autobiographic memory, Chinese Americans and other Asian Americans tend to recall collective, routine events within the family and neighborhood, whereas European Americans concentrate on individual perspectives.

According to Sarig (2016), reservations towards rating scales are unsurprising when considering the uniqueness principle that characterizes Adler's concept of lifestyle (personality). Mosak and Di Pietro (2006) proposed the idiographic lifestyle convictions approach to interpreting ERs. There is agreement in the literature regarding the procedure for collecting ERs, such as the distinction between specific recollections and a general description, the minimal number of ERs suitable for evaluation, and the need to request a focal point and the associated emotion, which is an important indication of the individual's subjectivity. Following Adler's attention to the value of identifying dominant themes in ERs, practitioners and researchers have focused on thematically interpreting ERs (Clark, 2002).

Among the only purely qualitative studies using ERs that we found in the literature were Tobin et al.'s (2007) study of the ERs of children and adolescents with reactive attachment disorder for thematic content. In Josselson's (2000) study, ERs were elicited from 24 participants at three time points over 22 years to explore ER stability and change through qualitative thematic analysis, and Canel's (2016) qualitative study examined connections between ERs and perceived parent schema. Our (Frank \& Shoshana, 2019) qualitative analysis of ERs examined the Adlerian construct of "social interest." We also recently conducted a qualitative study on ERs of high-SES adults (Levitt-Frank \& Shoshana, 2021).

Kromidas (2021) claimed that childhood memories shape the class, gendered, and raced subjectivities of mothers, and that memory work "is part of class formation" ( $p$. 37). According to Bamberg and Georgakopoulou (2008), the "work" individuals conduct as they interactively share a narrative contributes to a continuous process within which the sense of self emerges. As metaphoric narratives, ERs invite a unique qualitative examination of sense of self, culture, and class.

\section{Method}

This study adopted a qualitative approach to data collection and analysis, exploring the meaning associated with manifold cultural realities through the subjective experiences of individuals and groups (Creswell, 2013). Through their narratives, humans as storytellers ascribe meaning about themselves and others. This supports the concept of using narratives for research in disciplines such as psychology, sociology and education (Bruner, 1990). This study examined the complex viewpoints and self-concepts of individuals from low SES through the diverse expressions found in their ERs.

We recruited participants using the snowball method, in which initial participants approached by the researcher referred additional participants (Glesne, 2016). The sample included 12 male and female, low-SES, Israeli-born, Jewish, adult (30 to 67 years) respondents. Levinson (1986) signified adulthood as from the age of 30 years. All participants were independent decision-making and functioning adults (Arnett, 1998) and provided informed written consent to participate in the study prior to the interviews. The participants were part of a larger qualitative study that explored ERs of individuals from different social classes. We used pseudonyms for the participants quoted in this paper.

The Israeli Central Bureau of Statistics ranks all localities in Israel according to 16 socioeconomic variables, including average income per capita, average years of schooling, percentage of academic degree holders, and percentage of employees in academic or management occupations. That ranking produced 10 socioeconomic clusters. This study focused on respondents from Clusters 3 and 4 , which include the Israeli towns of Ashdod, Ashkelon, and Lod. In addition, we verified with each participant where they grew up, thereby ensuring that all participants' early childhoods were in the same SES environment.

Of the four participants who matriculated from high school, three held professional diplomas. Seven participants had completed 12 years of school, and one completed 9 years. Six participants were married with children, four were divorced with children, and two were single. All participants worked. Their occupations included a secretarial position, municipality or call center employees, housekeeping, home renovator, locksmith, and managers of cleaning contractors or of a printing center in an organization. Four interviews took place in the participants' homes, one in a park, and seven by telephone due to COVID-19 limitations. 
Nine participants were Mizrahi Jews (Middle Eastern or North African descent), one was Ashkenazi (European descent), and two were Mizrahi and Ashkenazi.

Since its foundation, Israel has demonstrated a correlation between ethnic affiliation and socioeconomic class. Mizrahi Jews tend to be less advantaged than Ashkenazi Jews in every SES aspect (Semyonov et al., 2015). This study's sample mirrored that stratification.

We conducted in-depth, semistructured interviews (40-60 min each) in Hebrew between August 2020 and December 2020. We informed participants that the study purpose was to learn about their leading values in life. The first part of the interview included a series of questions to elicit three to four ERs from each participant using procedures presented by Clark (2002) and Mosak and Di Pietro (2006). Example questions included, "Think back as far as you can in your childhood, to one of your earliest memories, preferably until the age of 10." Three ERs usually provide sufficient information for interpretation purposes (Clark, 2002). We asked participants to relay any ERs that came to mind. The ERs therefore reflected concepts, beliefs, and behavior patterns of the individuals without reference to a specific topic. We requested specific ERs rather than general childhood memories and collected a total of 42 ERs. The ERs ranged from the ages of 3 to 11 years; 17 of them were from earlier than 7 years of age. The second part of the interview included questions related to core values in life, self-perceptions, and plans.

This study used the grounded theory approach (Glaser $\&$ Strauss, 1967), conducive to revealing meaning without predefined hypotheses. People are rarely aware of how ERs reflect their perspectives, thereby increasing reliability and validity in research (Mosak \& Di Pietro, 2006). Incorporating a holistic framework, we examined the ERs principally following the lifestyle convictions approach (Mosak \& Di Pietro, 2006), which addresses perceptions such as self-concept (who and what I am) and self-ideal (what I should be to have a place and sense of belonging) to identify common and repeating themes (Shifron, 2020). In addition, we followed Sarig's (2016) approach and explored the ERs as narratives that include characters, introduction, and sequence of events. An experienced Adlerian therapist reviewed the primary analysis; then, we reread the ERs and further classified the themes that emerged as divided reality, living in the present, parental role, and social interest.

\section{Results}

The ERs in this study represented various topics-playing outside, playing with friends, food-related experiences, family experiences, kindergarten- or class-related experiences, war-related experiences, or death of a relative. Most
ERs begin with an introduction. In this study, an introduction preceded all ERs, creating story context. More than two thirds of the introductions were short. Others were longer, and some clearly delineated the transition between the introduction and the plot. For example, after introducing an ER, Yaacov says, "One day my brothers and I..." Participants create context in introductions to set themselves in time and place as part of a continuity of the self. Most mentioned the age or school grade; some mentioned a season or the day ("It was winter") or holiday ("It was Hanukkah"). Most introductions included geography-a town or specific location in the house or neighborhood. For instance, Eli says, "It was Saturday, in my parents' bed." More than half of the ERs took place at home or school/kindergarten. About a quarter occurred outside in the street, garden, yard, or an orchard. Others occurred at a friend or relative's house, and one at a family wedding. Parents (mothers and fathers equally) appeared in about half of the ERs, friends or peers in almost half, and siblings in 10 ERs. A grandparent appeared in only one ER.

When eliciting an ER, the interviewer asks for the dominant emotion present at the most vivid moment of the memory. We found 25 examples of positive emotions (e.g., happy, fun, good), 15 examples of negative emotions (e.g., sad, frustration, anger, terrible), and two examples of mixed emotions. Galya concludes one ER saying, "I felt protected." Dana says, "I was angry, sad, and disgusted." Yizhak, a youngest child, says, "I was both happy and sad. Happy at my sister's wedding; sad I would be alone [the only child] at home." Interestingly, despite the predominance of positive emotions, we found eight ERs describing difficult experiences. Shimon describes how a child at kindergarten fell during a game and was instantly blinded: "His head was bleeding." Yaffa says, "A man approached me... took me to the stairwell and lay on me.... I screamed, and he ran away."

We found one notable difference between men and women. Four male participants relayed seven ERs in which they saw themselves as "mischievous." Ilan, for example, says, "I was a really mischievous kid, restless and problematic." Yizhak says, "I was a small and mischievous kid." Reuben claims, "I was mischievous and king of the class." Only one woman, Becky, describes herself in one ER as "full of nonsense."

The data analysis revealed four themes, which together depicted the low-SES adults' concepts of self, others, and the world:

- Divided reality: the understanding of a social structure of categories and classes

- Creating meaning in the present: enjoying life and making do with what one has

- Parental role: admiration, security, and compensation 
- Social interest: an experience of connectedness and collaboration

\section{Divided Reality}

"There was always the ethnic issue, and also rich and poor."

We identified a perspective of divided reality among the low-SES adults in the sample, finding this viewpoint in 16 ERs, with at least one ER from nine participants. Divided reality in the ERs refers inter alia to social classes, strong and weak, winners and losers, big and small, popular versus unpopular, and beating the system. Becky's ER (Grade 1) demonstrates the perception of class division:

When I was small, we [children from our neighborhood] went to school in another [wealthy] neighborhood. There was always the ethnic issue, and rich and poor. It wasn't simple. We had to feel inferior all the time. On birthdays, they didn't want us. They suddenly said the party is over so that we would leave, and they would continue with the party. The girl said the party is over, and we had a gut feeling that it was not over, and we went back to check, and we were right. We confronted them. The feeling of being unwanted. Then we decided to do our own party privately. We always wanted to be a part of them, you understand?

What is the most vivid moment? "My friends standing outside."

The feeling? "Frustration and anger."

According to Shifron (2020, p. 212), "The most important information in an ER is the individual's strengths and creative abilities." Becky understands social structure and sees the world through class division. She compensates for feelings of inferiority ("We did our own party privately"). She is aware of the difference between the classes and the implications of inequality ("We had to feel inferior all the time"). This highlights her subjective sense of constraint, meaning, I do not have freedom of how to feel. Becky experiences and assesses herself (feeling inferior) through the eyes of the other group ("They didn't want us"). This experience of the self resembles the concept of double consciousness that Du Bois (2015) attributed to American Black people's experience at the turn of the century. He referred to the sensation of looking at oneself through the eyes of others: "Such a double life, with double thoughts, double duties and double social classes... must tempt the mind to pretense or revolt" (p. 153).

Despite the contextual constraint (Bourdieu, 1984) and the desire to belong ("We always wanted to be a part of them"), Becky and her friends confront the other children in an attempt to revolt and then create an alternative reality ("our own party"). Despite their resourceful initiative to create an alternative reality, the emphasis (most vivid moment) in the ER is standing outside, left out, and feeling frustrated and angry at this double-life experience, portraying a yearning for belonging with the other side.

In another ER (age 10 years), Becky further exemplifies the class division, the feeling of inferiority and looking at oneself through the eyes of another.

A girl [from the wealthy neighborhood] had a birthday party. We needed a ride home. Her dad was to drive us home. He said, "I will drop you at the school." We said, "Take us home." He wouldn't. On the Sunday at school, [the girl who had the party] said that we had sworn at her dad. Again, we felt this feeling of inferiority: The kids from the poorer neighborhood are swearing. Maybe we did, maybe we didn't, I couldn't remember.

What is the most vivid moment? "Sitting in the back seat."

What is the feeling? "I was always full of nonsense.

But in [her friends'] company, I was not. I was afraid. I chose every word, so they wouldn't think I was. . . . With the teachers, too. I wouldn't say an answer, even if I knew it, so I wouldn't look stupid. In the car, I felt in my comfort zone with my friends."

Becky reflects on the situation as she recalls the ER, engaging in psychological discourse more common in higher class circles (Shoshana, 2019). She feels at her best in her milieu, in her comfort zone. She has the courage to confront authority (the father). Becky sees herself labeled ("The kids from the poorer neighborhood are swearing") and depicts an existential experience of division and classes expressed through the metaphor of "sitting in the back seat." This ER serves as a joint metaphoric narrative for the phenomenological experience of adopting the perspective of oneself and the other ("so I wouldn't look stupid"), similar to what Mead (1934) called taking the role of the other, and the materialistic, "substance" (Bourdieu, 1984) guided experience of the lower class ("sitting in the back seat").

The divided reality portrayed in the ERs transcends class division. Reuven relays an ER (Grade 4) depicting a dichotomous view of society. There are winners or losers and strong or weak individuals.

There was a kid in the class. He was bright, gifted, but physically not so great. And me? I cannot lose. Never mind the idea that one should lose honorably. I was born with a winner streak. A fighter. It was recess. We were playing football. I shouted at him, "You don't know how to play! What is wrong with you, idiot? Don't play with us." We were not nice to him. I was the king of the class. None of the others said anything 
to me, like, shut up already or something. And this kid cried. I deserved a blow, as I insulted someone terribly. What is the most vivid moment? "I want to win." And the feeling? "No regrets; nothing bothered me."

Like Becky, Reuven reflects as we talk on the situation, his actions and cognitions as a child, and what he values today ("I insulted someone terribly"). In his description, he includes the values of losing honorably and respecting others. Drawing on his strengths (Shifron, 2020), he knows what is important to him as a child and as an adult and participates actively in social settings-a leader ("I was the king of the class"). Reuven's ER describes a world where the stronger rule and humiliate the weaker ("What is wrong with you, idiot"). An ER reflects present concepts about the self. Reuven maintains a complex concept of then and now, I and others, and right and wrong. He traces the trajectory between past and present and criticizes himself ("I deserved a blow"), intimating that he is not on the "strong side" today. At the end of the interview, he says, "I am not doing so well in life. Do you think I will be OK?" In his eyes, he is not strong, not the winner he should be.

Sara, too, illustrates a dichotomous view of society: "I remember in junior school there were the popular kids and the unpopular kids. I would go to great lengths to fit in."

Ilan emphasizes the concept of divided reality through the idea of beating the system in the following ER (age 6 years).

It was winter, December, and still warm outside. Officially winter but summer outside. I said to my dad, "Listen, I want to wear my winter pajamas." I loved my black winter pajamas. He said, "No. It is still summer. It is hot. You cannot wear long pajamas." I said, "I really like the pajamas. Let me wear [them]." He didn't want to let me. We had a closet with five glass doors (mirrors). I was mad and punched the mirror. I broke the glass in two. My dad was mad but did nothing.

What is the most vivid moment? "He brought me the pajamas after all."

And the feeling? "I beat the system."

Ilan knows what he wants and will do what it takes to get it. He recognizes the constraints of reality (it is winter but warm outside) yet remains focused on his desire. Ilan wants his pajamas no matter what. He found a creative strategy to make sure he got to wear his pajamas, persuading his father to give in. According to Adlerian theory, emotions are in the service of one's goals (Dreikurs Ferguson, 1984). Ilan got mad, enabling him to lose control and break the mirror and end up achieving what he wanted. By losing control, he controlled the situation and won. The emotion portrayed in the ER is an important clue to the individual's perception (Mosak \& Di Pietro, 2006). When asked how he felt, Ilan says, "I beat the system." He describes his primary goal in the ER: In social life, there is a system to beat. We suggest that "beating the system" may be a strategy to combat the lack of a sense of control over reality and contribute to an increased sense of autonomy and value (Deci \& Ryan, 2000; Manstead, 2018).

Yaffa's ER (age 4 years) further highlights the concept of a divided reality and the experience Becky termed "sitting in the back seat."

We had a balcony, overlooking the street, with the dining room table. I remember it was snowing. I was sick. A real fever. I feel bad and am burning up. I sat at the table and watched the kids playing outside in the snow. I felt so sorry for myself that I couldn't go out and play in the snow. They looked like they were enjoying themselves, having fun. I was envious of them. I wanted to join them.

What is the most vivid moment? "Me at the table, with my face stuck to the window."

And the feeling? "Self-pity. Me and them, they are all playing."

Yaffa reflects on her reality and on society. She is aware of the things she desires, out there, out of reach for her in life ("I was envious of them"). She knows what she wants. In her interview, Yaffa explains this concept lyrically: "I want to pay back my mortgage and then go study. It is something missing in my life, like a crochet needle, and I dropped a stitch. I need to fill in the stitch. It is missing." In the ER, she explains this current experience of yearning. She feels stuck on the inside ("my face stuck to the window").

We also see a yearning for belonging with the other side in Becky's ERs. Yearning connotes an intense, persistent, and future-oriented desire (Davis, 1984). Such a yearning for something other than "what I have" appeared in at least one ER of seven participants. Higher class children adopt a future-oriented agentic self to control one's future (Silva $\&$ Corse, 2018). We suggest that in lieu of the concept of a future-oriented agentic self, lower class individuals may maintain a yearning for the future when faced with a lack of control over circumstances.

Bourdieu (1984) claimed that working-class individuals distinguish between "inside and outside, or at home, and for others" (p. 200). Yaffa draws a line between the inside and the outside world, intimating that the outside world is preferable. To belong means to be with those outside, yet society is divided between "me and them." Yaffa's window metaphor, like Becky's back seat metaphor, evokes the veil image Du Bois (2015) used to describe the experience of the underprivileged: "Then it dawned upon me with a certain sadness that I was different from others, shut out from their world by a vast veil" (p. 8). Like Becky and Reuven, Yaffa maintains double consciousness (Du Bois, 2015), in her mind moving back and forth between the inside and the outside, seeing 
through the veil and feeling stuck behind it. The divided reality we find in the ERs extends beyond class division (Bourdieu, 1984). It includes a yearning for the future or for the other side and appears to be an internalized frame for assessing reality among low-SES individuals.

\section{Creating Meaning in the Present}

Social class creates differences in concept of the self and reality (Manstead, 2018). Low-SES individuals are invested in day-to-day survival and living. They are motivated by the need to deal with external constraints and threats (Manstead, 2018). We found the emphasis on creating meaning in the present among the low-SES adults in the sample in a total of 14 ERs, with at least one ER from six participants. Analysis of this theme revealed subcategories of enjoying life and making do with what one has.

\section{Enjoying Life}

The category of enjoying life appeared in at least one ER from four participants. Dana relays an ER (Kindergarten) that captures the experience of enjoying life:

It was winter. I love winter. We had an orchard behind our house. We went there with the kindergarten. There were many orange and lemon trees, and the teacher taught us how to climb a ladder with a bag and a picking tool. We picked oranges and sat in a circle eating, and someone came and told stories.

What is the most vivid moment? "The orchard, the orange trees."

And how do you feel? "Good, pleasant, with the smell of the blossoms."

This is a story about Dana's resources (Shifron, 2020). She knows what she loves. She collaborates with others and feels part of a group. Dana uses her senses to enrich her experience ("smell of the blossoms"). She learns from others ("The teacher taught us"), understands the value of working (climbing and picking), and enjoys being in the moment. The experience of involvement and enjoyment is called a Flow experience-full engagement with life in the present (Csikzentmihali, 1990). Dana describes such an experience, immersing herself in the orchard, the season, the social environment, and the activity. Nina's ER (age 8 years) portrays a similar idea:

It was recess. My friend and I exit the school gate. On the way home, we buy bread, slice it, and eat it with banana and sugar or chocolate. And we played around. What is the most vivid moment? "We are at her house, in the yard."

How do you feel? "Excellent. It was fun."
Nina is in the moment, fully engaged in the experience, making do with what there is, and enjoying it. She interacts with her friend and, together, they create meaning in the present. They rely on their own creativity and resourcefulness. When people feel in control of their actions, they feel a sense of enjoyment (Csikzentmihali, 1990). We suggest that in the absence of a sense of control over the environment and the future (Manstead, 2018), low-SES individuals develop a sense of control in the present, celebrated through joy in the moment. Dana and Nina celebrate life in their ERs. We propose this capacity to celebrate life and control the present is a creative mechanism to protect the self from the threats of the environment and the future. The sense of freedom (based on economic freedom) typical of high-SES individuals (Bourdieu, 1984) is replaced by an experience of enjoyment and living in the moment, as protection against the sense of constraint characteristic of low-SES individuals. Furthermore, this appears to be not only a creative protective mechanism, but also an asset, a capacity to create meaning and engage in the moment (Csikzentmihali, 1990).

\section{Making Do With What I Have}

"It was a good childhood because it wasn't bad."

Nina refers to having enough ("We had enough to eat"). She continues to describe her childhood in glowing terms: "It was fun. In the yard. We made pitot, burning our hands. We rode bicycles, played in the street, jumped rope." She explains the concept of making do: "It was a good childhood because it wasn't bad." The category of making do with what they have appeared in at least one ER from five participants. Yaacov's ER (age 8 years) highlights the idea:

I come home from school to a house with no food.

The tastiest food for us was the feet of a chicken. Not the drumstick, the feet. We ate what there was without complaining. Bread with margarine. Some was left over; mother made crumbs out of it with water and sugar. ... We had no worries despite the scarcity. We lived the fun and didn't think of tomorrow.

How did you feel? "We didn't think about it. That's what there is. But with lots of love."

Yaacov appreciates what he has, what life and his mother have to offer. Like Nina, he focuses on what there is, not what might be ("That's what there is"). He identifies the tastiest food among the options available. He recognizes his mother's creativity in making the most of the crumbs. Twice he repeats the phrase, "We didn't think." Whereas psychological discourse is common in high-class circles (Shoshana, 2019), Yaacov emphasizes that it seems safer not to think-not about the present or the future. Without the sense of economic freedom (Bourdieu, 1984) and opportunities, 
thinking about the future may be dangerous to survival in the present. Instead, Yaacov is fully engaged in the present, in every moment: "We lived the fun and didn't think of tomorrow." Tan et al. (2020) emphasized the positive connection between material resources and subjective well-being.

According to Csikzentmihali (1990), finding reward in the moment contributes to "emancipating oneself from social controls" (p. 19). Furthermore, strong materialistic values undermine the Flow tendency and are associated with poorer well-being (Isham et al., 2021). We suggest that making do with what one has and engaging in the present are important assets among low-SES individuals that allow a sense of freedom and contribute to subjective well-being. Whereas high-SES individuals are future focused (Carey \& Markus, 2017), we propose low-SES individuals embrace the present. We see this as a creative, multifaceted mechanism for resilience and a sense of autonomy and value, including joy of life, living in the moment, and celebrating what one has.

\section{Parental Role: Admiration, Security, and Compensation}

According to Kromidas (2021), childhood memories inform an individual's parenting philosophy. Lareau (2011) characterized working-class parental strategies as natural growth emphasizing love, food, and safety as a basis for growing and developing. We found reference to the parental role in 22 ERs, with at least one ER from all participants. We identified a strong parental presence, including love, caring, security, and safety, as well as compensation for experienced difficulties. We noticed admiration and deep appreciation towards the parent (mother or father). Galya's ER (Grade 2) captures the essence of this admiration and parental presence:

We had a school trip. Father would leave money for Mother in the morning for groceries. I hadn't bought snacks, so I said I will go by the grocery store. Mother said, "Take whatever snack you want." I bought crisps. The man said, "You must pay me now." I said, "Mother will come by shortly or Father this afternoon." He didn't accept it. I stressed out and was insulted. Mother said, "Why not?" I said, "Because of the money." Wow. She came to him and said, "Listen!" Nothing could stop her. She always saw us. Each of us was like a single child. Her love and warmth were rare. She said, "My husband will come at 1:30 pm. You've known me for years." They argued. She said to me, "Take the crisps and put the packet in your bag. Go to school so you won't be late." She said to him, "Don't worry, I will bring the money. I don't have enough now; I will bring it later." I felt her caring. I always have someone to rely on. I have support. She will solve everything for me.
What is the most vivid moment? "The support. She gives me the crisps and says, 'Put it in your bag.' And I say, 'But we haven't paid.' And she says, 'Open your bag and put the crisps in.'”

How did you feel? "Protected. A bit uncomfortable for the man, but I trusted Mother that things will work out."

Galya fully trusts her parents as providers and protectors. She appreciates them and feels protected. Father works and leaves money every morning for mother. Mother makes sure Galya has a snack and sends her to the store. In Galya's eyes, mother would do anything for any of her children ("Each of us was like a single child.... Her love and warmth were rare"). The parental role reflected in this ER is to care for the children, protect them from harsh reality ("The man said, 'You must pay me now"), and ensure they lack nothing ("Put the crisps in your bag, I will bring the money later"). Parents do what they can for their children, love and protect them, and are not taken for granted. Yaacov's ER, too, shows he appreciates his mother's love and hard work: "Mother made crumbs out of bread with water and sugar... lots of love."

Lareau (2011) mentioned the parental role of comforter among low-SES parents. We see this role sometimes emerge as a compensatory role. Hoff et al. (2002) claimed that, on average, low-SES parents are authoritative and punitive when their authority is countermanded. Ilan's father gave him the pajamas despite Ilan breaking the mirror. The father not only does not punish Ilan, but also compensates him for his frustration. In another of Galya's ERs (Kindergarten), she describes an incident when she told her mother that she wanted another meatball for lunch, and the teacher did not give her one. Galya's mother compensates: "I felt so much love from Mother, who wanted to compensate me for the bad feeling I had and said she would make some [meatballs] at home."

Sara shares an ER (age 11 years) where she cannot go on a trip to Germany with her handball team due to illness:

My father said, "Never mind how much the trip costs. I will give you the money for you to use as you wish." So that I wouldn't feel the disappointment, so it wouldn't be hard for me. I felt I was missing out on the experience.

Sara's father wants to compensate her for missing out, as she explains. It appears that like Galya's and Ilan's parents, Sara's father's motive is to alleviate any hard feelings or frustration. Isaac describes how his father did everything possible to ensure he would have a better future. "I made a lot of trouble at school.... The teacher said to my dad, 'He received a grade of zero this semester."' Isaac's father found colleagues at work to study with 
him every day to improve his grades, despite him being a troublemaker.

Galya and Yaacov are aware of the economic constraints and see their parents rise above them. This is not the sense of entitlement characteristic of high-SES individuals (Levitt-Frank \& Shoshana, 2021; Lareau, 2011), but a sense of deep appreciation. Galya says, "Mother always saw us." Galya, Yaacov, and Shimon see their parents. Shimon's ER (age 11 years) takes the protector metaphor a step further and portrays father as a savior:

The Six Day War broke out. We lived by the walls of the old city [Jerusalem]. I was playing outside on the street. Suddenly, there was sniper shooting and sirens. I am near to death. I lay on the ground. Scared. It was traumatic.

What is the most vivid moment? "My father crawled from the house to search for me and took me home. I saw him as a savior."

Shimon is resourceful. He likes to play and keep himself happy. He knows reality can be dangerous, scary, and unpredictable. In his ER, we see the experience of having no control over circumstances ("suddenly;" Manstead, 2018). His father appears as a savior, almost omnipotent, saving him from danger of death. We suggest that low-SES parenting goes beyond "natural growth," comforting (Lareau, 2011), and directive, authoritative strategies (Hoff et al., 2002); it includes taking on the role of creating safety and stability to compensate for hard feelings and experienced lack of control over life circumstances. Compensation for disappointments or the experience of scarcity or harsh reality appears to be a parental strategy low-SES parents adopt.

\section{Social Interest: An Experience of Connectedness and Collaboration}

According to Adlerian theory, social interest-an immanent potentiality for collaboration and feeling part of the group that manifests in cognitive, emotional, and behavioral patterns such as empathy and cooperation-needs to be nurtured in childhood. The feeling evoked by social interest is one of togetherness (Frank \& Shoshana, 2019). We identified the theme of social interest in a total of 21 ERs, with at least one ER from eight participants. Collaborative experiences and plural language characterize these ERs. Sara's ER (age 5 years) depicts this feeling:

I remember where we lived-the people, the butcher, and the grocer. Our parents always took care of us with a lot of love. We were moving to another apartment. There was a truck. My parents and siblings were on the truck ready to go. And they forgot me for a moment. My uncle shouted to my mother, "Stop, you left Sara here."
And they lifted me onto the truck. There was chaos for a few minutes.

What is the most vivid moment? "The truck and the whole family."

And the feeling? "The whole family is united."

Sara's ER opens with a picture of a community setting. Using the plural, we, Sara describes the neighborhood ("the people, the butcher, and the grocer"). She feels part of the family and the community and emphasizes the parental role of caring and love. Sara feels part of the group, even when left behind. The sense of togetherness is strong enough to overcome the experience of being forgotten and the chaos. She expresses her guiding values of collaboration (uncle helped) and being together ("united").

Dana (Kindergarten) also uses the plural, we, and the word, all, referring to the group: "We were all siting together, a group of children, around the table, all dressed in long winter clothes. We had hot soup. I felt safe." She portrays a participatory group experience. For Dana, being together means feeling safe. Yaacov highlights the concept or working together in three of his ERs. In one ER (age 10 years), he describes working with mother: "Mother and I were working in the garden,... turning the soil, me with the garden fork." We refer to Dana's ER (Kindergarten) about picking oranges and lemons to demonstrate enjoying life. Dana associates the value of working together with enjoying life as part of a group: "We picked oranges and sat in a circle eating."

Yaacov's and Dana's ERs reflect working together with others as part of life. They achieve a feeling of togetherness through active collaboration, doing their part in the social setting. It appears safer to be together. Low-SES individuals tend to maintain ties and regard themselves as connected with others and interdependent (Carey \& Markus, 2017). Group membership appears central to the concept of self among lowSES individuals. Piff et al. (2010) suggested that the prosocial behavior characteristic of low-SES individuals may promote trust and collaboration to ensure that, in times of adversity, their needs will be met by others. Social interest promotes well-being and resilience (Adler, 1931). We propose that group membership and an interdependent contextualized concept of self, characteristic of low-SES individuals (Manstead, 2018), may be seen as a manifestation of social interest. We believe that social interest, coupled with the ability to be fully engaged in the present and making do with what one has, contributes to a subjective sense of well-being.

\section{Discussion}

This study offers an innovative examination of the convergence between ERs, self and others, and low SES. It draws on the psychology of social class and the implications of 
social class for self and identity patterns and processes (Easterbook et al., 2020; Greitemeyer \& Sagioglou, 2018; Mao $\&$ Feldman, 2019; Stephens et al., 2014). We emphasize the reciprocal trajectory between past and present in human perceptions, as expressed through ERs-metaphoric representations of adults' current schemas. We use ERs to reveal cultural significance through the exploration of individuals' subjective perceptions about themselves and the world. The study contributes to the understanding of class-related psychological processes and offers a unique qualitative framework for exploring cultural contexts.

In this study, we explore how low-SES individuals understand themselves and their childhoods through the psychological expressions self-depicted in their ERs. We find that low-SES individuals have a deep understanding of the dichotomous structure of social life. Their experience of connectedness and collaboration, together with the ability to create meaning and joy in the present, appears to be a creative mechanism for resilience, autonomy, and a sense of value and contributes to a subjective sense of well-being. The parental role in low SES that emerges from our data is a vibrant one. We discover active parenting with a strong presence in their children's lives.

According to Khan (2021), a prominent characteristic of teenage elite members is their ability to conduct themselves with ease in all circumstances and to experience hierarchy as natural. The perception of a divided hierarchical world reflected through the ERs-one that goes beyond class division (wealthy and poor, weak and strong, winners and losers, us and the system)-resonates with the feeling of constraint that Bourdieu (1987) described, as opposed to the freedom from constraints and transparency that high-SES individuals experience. This feeling of constraint appears to manifest in the yearning for the other side that we identified in some ERs. We regard yearning, a continual future-oriented desire (Davis, 1984), as an active form of overcoming a sense of lack of control over circumstances or a general state of lacking something in life.

High-SES individuals experience a sense of freedom and control of their present and future reality, whereas low-SES individuals experience a sense of constraint and focus on the present because they are invested in survival and need to deal with external threats (Levitt-Frank \& Shoshana, 2021; Bourdieu, 1984; Carey \& Markus, 2017; Manstead, 2018). Csikzentmihali (1990) focused on the Flow experience of full engagement and joy in the present. We found the capacity to celebrate life and what one has and to fully engage in the present to be a classrelated creative mechanism for dealing with life.

According to Adler (1931), human beings create and ascribe meaning to life. They "live in the realm of meanings" (p. 15). We regard the existential preoccupation with the joy of life, including celebrating what one has, to be a form of creating meaning characteristic of working-class individuals. We suggest that this creative meaning-making mechanism helps protect the self from external, structural, and oppressive threats and from an experienced lack of control over the future. According to Adlerian theory, all individuals strive to feel a sense of belonging and value and hence create strategies for belonging (Dreikurs Ferguson, 1984; Shifron, 2020). The desire to "beat the system" (us vs. them) also may be part of a class-related strategy for retaining a sense of belonging and value by gaining a sense of control and overcoming the Bourdieusian sense of constraint (Bourdieu, 1984).

According to Lareau $(2002,2011)$, working-class parenting strategies emphasize the accomplishment of natural growth and focus on love, safety, comfort, physical care, and teaching the difference between right and wrong. "Working class parents viewed children's development as spontaneous as long as they were provided with comfort, food, shelter, and other basic support; sustaining children's natural growth despite formidable life challenges is probably viewed as an accomplishment" (Lareau, 2002, p. 773). The term, natural growth, seems to imply a more laissez faire, passive form of parenting than the higher class's concerted cultivation style of parenting that, as Lareau described, "creates a frenetic pace for parents" (p. 748). Higher class parents are described as fully involved in their children's lives, organizing their activities, training them in the rules of the game (such as coping strategies in institutions and with authority figures), and cultivating their sense of entitlement.

Our study reveals a concept of working-class parents as active, fully present, and involved in their children's lives. The adults interviewed express profound admiration for their parents through their ERs. We see appreciation towards parents and their exerted efforts to provide love, comfort, safety, and a buffer between the children and the reality around them. Parents are perceived as sensitive to their children's pain and difficulties, often due to their lower SES status. We find a parental strategy of compensation for experienced hardships. We propose that this impelling strategy of compensation among working-class parents appears as an attempt to balance the lack of resources and experienced sense of constraint.

Tan et al. (2020) suggested that money and resources are related to subjective well-being. According to Adler (1931), the capacity for social interest is crucial for mental health and resilience. The interdependence and empathy towards others characteristic of low-SES individuals provides bonding capital, which leads to positive outcomes (Carey \& Markus, 2017). We believe that group membership, connectedness, and interdependence (Carey \& Markus, 2017; Manstead, 2018) as an expression of social interest, together with the ability to create meaning in the present, contribute to a subjective sense of well-being. According to Czikszentmihalyi (1990), Flow is a source 
of energy that can be well used or misused. "The task is to learn how to enjoy everyday life without diminishing other people's chances to enjoy theirs" (p. 70). We suggest that Flow without social interest may be misused. Introducing the concept of social interest together with the notion of Flow and creating meaning in the present may enrich educational and therapeutic strategies across social classes.

Positive psychotherapy emphasizes a strengths-based growth approach (Lavy, 2020; Rashid, 2015). This study exposes the strengths and resources expressed in the ERs. Davies and Rizk (2018) referred to a generative micro-oriented form of cultural capital. We believe that working-class individuals develop creative strategies and mechanisms to deal with a lack of control and resources, sense of constraint, and hierarchical and classed society. We encourage educational and therapeutic frameworks to recognize the creativity and resourcefulness portrayed in these strategies and to consider them as facets of psychological and cultural capital.

\section{Limitations and Future Research}

We conducted a qualitative exploration of the ERs collected in this study. Although the sample size of 12 participants and 42 ERs is adequate for this kind of research (Guest et al., 2006), it may limit the ability to generalize and validate our findings. It may be interesting for a future study to focus on more specific age groups rather than our range of 30 to 67 years. Our research presented no significant gender differences, but future research with a different sample size may generate different results. This research on the convergence of ERs, self and others, and low SES invites a future comparative view between ERs of low- and high-SES individuals and the exploration of ERs of socially mobile individuals. Additionally, we encourage further and varied research using ERs, including strengths and resources in ERs, to enrich the literature and clinical application of ERs.

Funding No funding, grants or other support was received for conducting this study or for assistance with the preparation of this manuscript.

\section{Declarations}

Conflict of interest The authors confirm that they have no conflict of interest. They have no relevant financial or non-financial interests to disclose.

Ethical approval This study received ethical approval from the Ethics Committee for Research with Human Beings, Faculty of Education, University of Haifa, Israel. The approval number from the Ethics Committee is $408 / 19$.

\section{References}

Adler, A. (1931). What life should mean to you. Little Brown.

Allers, C. T., White, J., \& Hornbuckle, D. (1992). Early recollections: Detecting depression in college students. Journal of Individual Psychology, 48(3), 324-329.

Arnett, J. J. (1998). Learning to stand alone: The contemporary American transition to adulthood in cultural and historical context. Human Development, 41, 295-315. https://doi.org/10. $1159 / 000022591$

Attarian, P. J. (1978). Early recollections: Predictors of vocational choice. Journal of Individual Psychology, 34(1), 56-62.

Bamberg, M., \& Georgakopoulou, A. (2008). Small stories as a new perspective in narrative and identity analysis. Text and Talk, 28(3), 377-396. https://doi.org/10.1515/TEXT.2008.018

Barrett, D. (1980). The first memory as a predictor of personality traits. Journal of Individual Psychology, 36(2), 136-149.

Bourdieu, P. (1984). Distinction: A social critique of the judgment of taste (R. Nice, Trans.). Boston: Harvard University Press.

Bourdieu, P. (1987). What makes a social class? On the theoretical and practical existence of groups. Berkeley Journal of Sociology, 32, 1-17.

Bruner, J. (1990). Acts of meaning. Harvard University Press.

Calarco, J. M. (2018). Negotiating opportunities: How the middle class secures advantages in school. Oxford University Press.

Canel, A. N. (2016). Compatibility of the relationship of early recollections and life style with parent schemas obtained through Adlerian interviews. Educational Science: Theory \& Practice, 16(3), 891-914. https://doi.org/10.12738/estp.2016.3.2886

Carey, R. M., \& Markus, H. R. (2017). Social class shapes the form and function of relationships and selves. Current Opinion in Psychology, 18, 123-130. https://doi.org/10.1016/j.copsyc. 2017.08.031

Clark, A. J. (2002). Early recollections: Theory and practice in counseling and psychotherapy. Brunner-Routledge.

Côté, S. (2011). How social class shapes thoughts and actions in organizations. Research in Organizational Behavior, 31, 43-71. https://doi.org/10.1016/j.riob.2011.09.004

Creswell, J. W. (2013). Qualitative inquiry and research design: Choosing among five approaches. Sage.

Czikszentmihalyi, M. (1990). Flow: The psychology of optimal experience. Harper \& Row.

Davis, W. A. (1984). The two senses of desire. Philosophical Studies, 45(2), 181-195. https://doi.org/10.1007/BF00372477

Davies, S., \& Rizk, J. (2018). The three generations of cultural capital research: A narrative review. Review of Educational Research, 88(3), 331-365. https://doi.org/10.3102/0034654317748423

Deci, E. L., \& Ryan, R. M. (2000). The "what" and "why" of goal pursuits: Human needs and the self-determination of behavior. Psychological Inquiry, 11(4), 227-268. https://doi.org/10.1207/ S15327965PLI1104_01

Dreikurs Ferguson, E. (1984). Adlerian theory: An introduction. Adler School of Professional Psychology.

Du Bois, W. E. B. (2015). The souls of black folk. Yale University Press.

Easterbrook, M. J., Kuppens, T., \& Manstead, A. S. (2020). Socioeconomic status and the structure of the self-concept. British Journal of Social Psychology, 59(1), 66-86. https://doi.org/10. $1111 /$ bjso. 12334

Fakouri, M. E., \& Hafner, J. L. (1984). Early recollections of firstborns. Journal of Clinical Psychology, 40(1), 209-213. https:// doi.org/10.1002/1097-4679(198401)40:1\%3C209::AID-JCLP2 270400141\%3E3.0.CO;2-4

Frank, M. L., \& Shoshana, A. (2019). "It was a kind of togetherness feeling": An Exploration of Social Interest in Early 
Recollections. The Journal of Individual Psychology, 75(1), $42-57$.

Glaser, B., \& Strauss, A. L. (1967). The discovery of grounded theory. Aldine.

Glesne, C. (2016). Becoming qualitative researchers: An introduction. Pearson.

Greitemeyer, T., \& Sagioglou, C. (2018). Does low (vs high) subjective socioeconomic status increase both prosociality and aggression? Social Psychology, 49(2), 76-87. https://doi.org/10.1027/18649335/a000331

Grossmann, I., \& Huynh, A. C. (2013). Where is the culture in social class? Psychological Inquiry, 24(2), 112-119. https://doi.org/10. 1080/1047840X.2013.792568

Guest, G., Bunce, A., \& Johnson, L. (2006). How many interviews are enough? An experiment with data saturation and variability. Field Methods, 18(1), 59-82. https://doi.org/10.1177/2F152 5822 X05279903

Hoff, E., Laursen, B., \& Tardiff, T. (2002). Socioeconomic status and parenting. In M. H. Bornstein (Ed.), Handbook of parenting (2nd, Eds pp 231-252). Erlbaum.

Isham, A., Gatersleben, B., \& Jackson, T. (2021). Materialism and the experience of flow. Journal of Happiness Studies, 22(4), 17451768. https://doi.org/10.1007/s10902-020-00294-w

Josselson, R. (2000). Stability and change in early memories over 22 years: Themes, variations, and cadenzas. Bulletin of the Menninger Clinic, 64(4), 462-481.

Khan, S. R. (2021). Privilege: The making of an adolescent elite at St. Princeton University Press.

Kromidas, M. (2021). "When I was a kid:" Childhood memories, care work, and becoming mom. Subjectivity, 1-17. https://doi.org/10. 1057/s41286-021-00113-4

Lamont, M., \& Lareau, A. (1988). Cultural capital: Allusions, gaps and glissandos in recent theoretical developments. Sociological Theory, 6(2), 153-168. https://doi.org/10.2307/202113

Lareau, A. (2002). Invisible inequality: Social class and childrearing in black families and white families. American Sociological Review, 67(5), 747-776. https://doi.org/10.2307/3088916

Lareau, A. (2011). Unequal childhoods: Class, race, and family life. University of California Press.

Lavy, S. (2020). A review of character strengths interventions in twentyfirst-century schools: Their importance and how they can be fostered. Applied Research in Quality of Life, 15(2), 573-596. https:// doi.org/10.1007/s11482-018-9700-6

Levinson, D. J. (1986). A conception of adult development. American Psychologist, 41(1), 3-13. https://doi.org/10.1037/0003-066X. 41.1.3

Levitt-Frank, M., \& Shoshana, A. (2021). An Experience of Entitlement: The Intersection of High Socioeconomic Status, Self, and Early Recollections. Ethos, 49(2), 216-236.

Manaster, G. J., \& Perryman, T. B. (1974). Early recollections and occupational choice. Journal of Individual Psychology, 20, 232-237.

Manstead, A. S. (2018). The psychology of social class: How socioeconomic status impacts thought, feelings, and behavior. British Journal of Social Psychology, 57(2), 267-291. https://doi.org/10. 1111/bjso. 12251

Mao, J., \& Feldman, E. (2019). Class matters: Interviewing across social class boundaries. International Journal of Social Research
Methodology, 22(2), 125-137. https://doi.org/10.1080/13645579. 2018.1535879

Markus, H. R., \& Stephens, N. (2017). Editorial overview: Inequality and social class; the psychological. Current Opinion in Psychology, 18, 1-8. https://doi.org/10.1016/j.copsyc.2017.11.001

Mead, G. H. (1934). Mind, self and society (Vol. 111). University of Chicago Press.

Mosak, H., \& Di Pietro, R. (2006). Early recollections: Interpretive method and application. Routledge.

Piff, P. K., Kraus, M. W., Côté, S., Cheng, B. H., \& Keltner, D. (2010). Having less, giving more: The influence of social class on prosocial behavior. Journal of Personality and Social Psychology, 99(5), 771-784. https://doi.org/10.1037/a0020092

Rashid, T. (2015). Positive psychotherapy: A strength-based approach. Journal of Positive Psychology, 10(1), 25-40. https://doi.org/10. 1080/17439760.2014.920411

Sarig, G. (2016). A transparent childhood train: On Adlerian work with early recollections [Hebrew]. Mofet.

Semyonov, M. R., Raijman, R., \& Maskeylison, D. (2015). Ethnicity and labor market incorporation of post-1990 immigrants in Israel. Population Research and Policy Review, 34(3), 331-359. https:// doi.org/10.1007/s11113-014-9345-6

Shifron, R. (2020). The miracle of early recollections in Adlerian psychotherapy and supervision. Journal of Individual Psychology, 76(1), 110-127. https://doi.org/10.1353/jip.2020.0022

Shoshana, A. (2019). Youth, class, and happiness. Children and Youth Services Review, 99, 64-73. https://doi.org/10.1016/j.childyouth. 2019.01.034

Silva, J. M., \& Corse, S. M. (2018). Envisioning and enacting class mobility: The routine constructions of the agentic self. American Journal of Cultural Sociology, 6(2), 231-265. https://doi.org/10. 1057/s41290-017-0026-X

Snibbe, A. C., \& Markus, H. R. (2005). You can't always get what you want: Educational attainment, agency, and choice. Journal of Personality and Social Psychology, 88(4), 703-720. https://doi. org/10.1037/0022-3514.88.4.703

Stephens, N. M., Cameron, J. S., \& Townsend, S. S. (2014). Lower social class does not (always) mean greater interdependence: Women in poverty have fewer social resources than working-class women. Journal of Cross-Cultural Psychology, 45(7), 1061-1073. https://doi.org/10.1177/0022022114534768

Tan, J. J., Kraus, M. W., Carpenter, N. C., \& Adler, N. E. (2020). The association between objective and subjective socioeconomic status and subjective well-being: A meta-analytic review. Psychological Bulletin, 146(11), 970-1020. https://doi.org/10.1037/ bu10000258

Tobin, D., Wardi-Zonna, K., \& Yezzi-Shareef, A. M. (2007). Early recollections of children and adolescents diagnosed with reactive attachment disorder. Journal of Individual Psychology, 63(1), 86-95.

Wang, Q. (2016). Remembering the self in cultural contexts: A cultural dynamic theory of autobiographical memory. Memory Studies, 9(3), 295-304. https://doi.org/10.1177/2F1750698016645238

Publisher's Note Springer Nature remains neutral with regard to jurisdictional claims in published maps and institutional affiliations. 